\title{
Aventura Matemática
}

\author{
Walber A. R. Beltrame', Kenia D. S. Baeta ${ }^{1}$, Marcos R. de Souza ${ }^{1}$, Daniel F. S. D. \\ Piassi $^{1}$, Gabriel da S. Reboli ${ }^{1}$, Samuel L. M. Sezini' ${ }^{1}$, Thaysa S. Favatto ${ }^{1}$ \\ ${ }^{1}$ Instituto Federal do Espírito Santo (IFES) - Campus Guarapari \\ Alameda Francisco Vieria Simões, 720 - Aeroporto, Guarapari - ES, 29216-795 \\ \{walber.beltrame, kenia.dutra\}@ifes.edu.br, \{plog12gcp, dfsdpiazzi, \\ gabrielreboli, samuelsezini, thaysasouzaf\}@gmail.com
}

\begin{abstract}
Resumo. Este artigo visa detalhar um jogo educacional como facilitador dos estudos sobre operações matemáticas elementares dos últimos anos do Ensino Fundamental, o Aventura Matemática, construido de forma multidisciplinar entre professores e alunos dos últimos anos do Ensino Médio, a partir de um projeto de iniciação científica júnior. São apresentados desafios pedagógicos e formas de aplicação do jogo para dispositivos móveis. É feito uma análise do processo de desenvolvimento com metodologias ágeis colaborativas, como um método organizador dos estudos de criação e programação de jogos por estudantes de nível técnico. As telas e funcionalidades são discutidas e uma avaliação do jogo foi realizada, por meio de questionários enviados a um grupo de alunos com reforço escolar, apresentando resultados satisfatórios e potenciais melhorias.
\end{abstract}

\section{Cenário de uso}

O jogo educacional Aventura Matemática [Beltrame et al. 2017] pode ser considerado um objeto de aprendizagem resultante do projeto de iniciação científica júnior do Ifes Guarapari, de modo multidisciplinar entre docentes de Matemática e Informática e um grupo de cinco alunos dos últimos anos do Ensino Médio integrado ao Técnico, cuja motivação fora que parte dos alunos ingressantes na escola apresentam dificuldades com operações aritméticas básicas, referente aos conteúdos dos últimos anos do Ensino Fundamental.

Essas dificuldades ocasionam um número elevado de reprovações no primeiro ano das matérias de exatas. Ainda que o colégio realize projetos de reforço escolar, outros dificultadores são encontrados, principalmente quanto ao acesso a conteúdos e exercícios corrigidos desses programas anteriores, dado ser uma escola secundária e os materiais de escola primária. Dessa forma, um dos desafios pedagógicos que o jogo percorre é mediar interações com esses currículos por meio de um jogo educacional para dispositivos móveis [Beltrame et al. 2017].

O jogo permite que o aluno acesse as matérias de modo lúdico e divertido, por meio de resumos, questões e desafios, distribuídos em cenários, a fim de tornar a Matemática atraente, acessível e em linguagem simples. No próximo capítulo é feito uma análise do processo de desenvolvimento do projeto por metodologias ágeis, como método organizador dos estudos de criação e programação de jogos por estudantes de nível técnico. As telas e funcionalidades são discutidas e uma avaliação do jogo foi realizada, como etapa do projeto, por meio de questionário enviado para alunos de reforço escolar, com resultados satisfatórios e potenciais melhorias. 
VII Congresso Brasileiro de Informática na Educação (CBIE 2018)

Anais dos Workshops do VII Congresso Brasileiro de Informática na Educação (WCBIE 2018)

\section{Desenvolvimento}

Para construção do jogo seguiu-se uma metodologia de aprendizagem por projetos, a partir da adaptação de algumas práticas [Medeiros et al. 2017][Nunes et al. 2017]. O projeto foi dividido em planos de trabalho por competências relacionadas a tecnologia de criação de jogos: (1) modelagem de jogos, edição de imagens e animações na forma vetorial; (2) programação e manipulação de motor de jogos avançado, com capacidade de compilação para dispositivos móveis; (3) edição de conteúdos multimídia, como hipertextos e vídeos, para apresentação dos conteúdos digitais.

Apesar da divisão de tarefas por área de interesse, algumas atividades foram realizadas colaborativamente (Figura 1). Para fins de compreensão desse modelo, podese dividir o processo didático em três grandes componentes: (1) Gestão de Projetos, em que são incentivados técnicas segundo os princípios ágeis e ferramentas de trabalho, como o Scrum [Medeiros et al. 2017]; (2) Fases Práticas, em que se equilibram os planejamentos e procedimentos ágeis com as atividades de construir e aprender, a partir de soluções reais para um problema desafiador [Nunes et al. 2017]; (3) Mediação da aprendizagem, em que um conjunto de atividades cíclicas são propostas para promover desequilíbrios epistêmicos e reconstrução dos saberes sobre as habilidades desejadas, no caso, sobre criação de jogos.

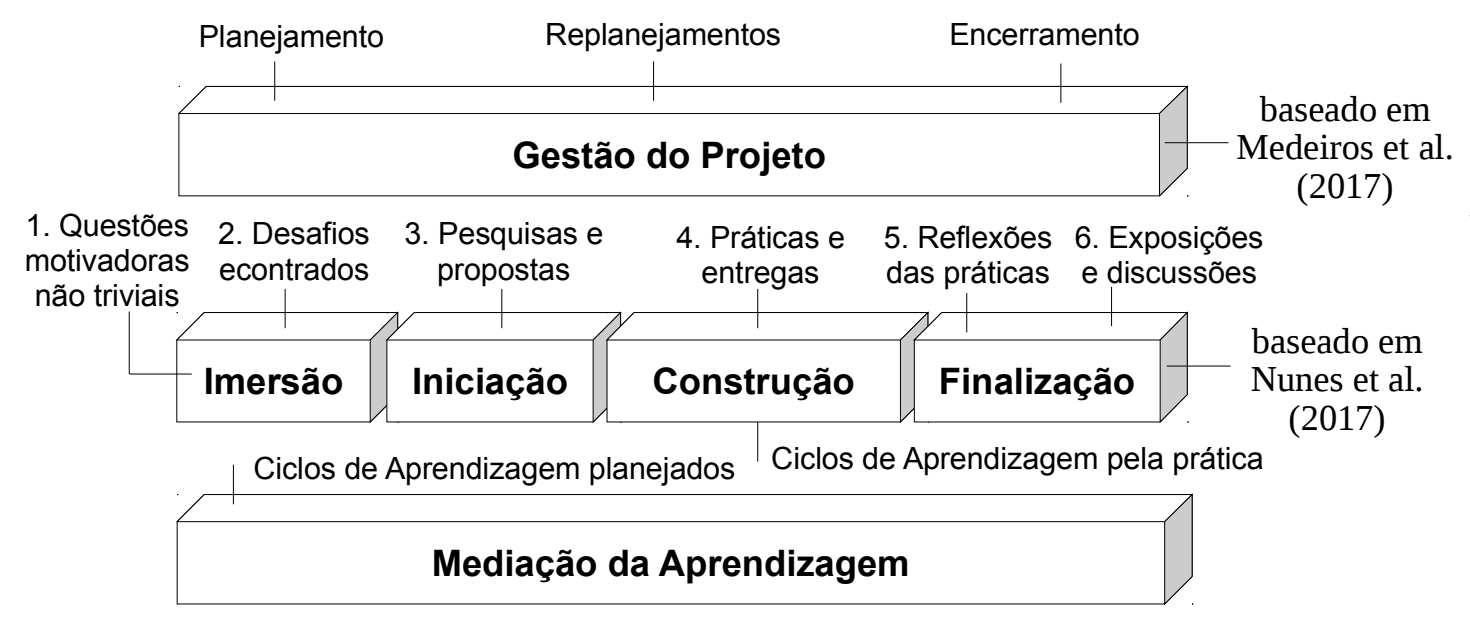

Figura 1. Modelo de atividades para construção do jogo educacional

Quanto à Gestão do Projeto, cada atividade prática é planejada e replanejada pelos orientadores, segundo diretrizes ágeis, como entregas parciais (sprints), reuniões constantes e feedbacks. O primeiro ponto é encontrar uma temática sobre questões não triviais, diretamente relacionadas ao contexto possível a ser explorado pelos estudantes e que despertem interesse, autonomia e curiosidade [Freire, 1998]. Durante o percurso, os desafios são estímulos para ações direcionadas de aprendizagem quanto às Fases Práticas:

1. Questões Motivadoras não triviais: discutidas em reuniões entre os cinco alunos selecionados, organizadores, participantes do curso de reforço e dois professores orientadores. Os desafios foram apresentados por todos, assim como ideias e assuntos relacionados foram expostos e anotados pelos estudantes, de forma que esses encontros motivaram empatia entre o grupo; 
2. Desafios encontrados: nessa etapa foram realizadas pesquisas e análises de perfil dos estudantes que faziam reforço, por meio de questionário inicial aplicado aos quarenta e cinco participantes. Foi constatado que alternavam-se entre aqueles que estudavam com frequência e os que não tinham costume, mas eram poucos aqueles que complementam os estudos com materiais auxiliares. Outro ponto a se destacar foi que a maior parte concordou com a proposta de um jogo para celular. As respostas descritivas auxiliaram na identificação de requisitos funcionais e não funcionais, por exemplo, não precisar de conexão com Internet;

3. Pesquisas e propostas: nessa etapa os estudantes foram orientados a pesquisar soluções já existentes, avaliarem esses jogos, ver pontos fortes e fracos. Deviam propor ideias para o jogo, fazer e refazer rascunhos para as telas, pesquisar teorias sobre como fazer um jogo educacional e validar com os professores as propostas. A partir dessas definições, planejamentos, divisões de tarefas e priorizações sobre as práticas de construção e de programação do jogo foram iniciadas (sprints);

4. Práticas e entregas: nesse momento as responsabilidades e as tarefas para criação do jogo foram executadas na forma de sprints do método Scrum [Medeiros et al. 2017] e, a cada período quinzenal, os alunos e os orientadores se reuniam para discutir as entregas e evoluções do jogo, tirar as dúvidas sobre programação, desenho ou edição multimídia. Considera-se que tais atividades são interações de aprendizagem pela prática e, além de se trabalhar as habilidades individuais, buscavam-se aprendizados pelo trabalho coletivo. Anotavam-se detalhes importantes em diários de bordo e a avaliação era feita tanto pela qualidade das entregas quanto pelas atitudes comportamentais;

5. Reflexões das práticas: durante essa etapa os alunos disponibilizaram o jogo para testes e foram orientados a elaborar um questionário avaliativo [Beltrame et al. 2017]. A partir da análise de respostas dos participantes, debateram sobre o trabalho desenvolvido, apresentaram pontos positivos e negativos, principais dificuldades e resultados perante aos desafios iniciais propostos;

6. Exposições e discussões: nessa fase final os estudantes submeteram o jogo para várias exposições, desde mostra de ciências da própria escola, mostra de ciências municipal e estadual, até em eventos de nível nacional [Beltrame et al. 2017], a fim de estimular comunicação interpessoal, as lideranças e as habilidades de diálogo com a sociedade. Essas relações traziam novas discussões e visões sobre o jogo, com novas possibilidades de melhoria e de correções. Explorou-se a noção de pertencimento ao mundo, protagonizando ações importantes diante das dificuldades, não somente do colégio, mas da comunidade. 
Durante cada marco anterior, atividades planejadas de estudos foram propostas pelos orientadores, quanto à Mediação da Aprendizagem. Esses planejamentos tinham como concepção pedagógica de Piaget (1929-1979) e Vygotsky (1978), dado que as práticas eram complementadas com interações questionadoras, motivando o processo de desequilíbrio epistêmico, reconstrução do saber e socialização do aprendizado. Dessa forma, antes de tentar codificar um botão do jogo, por exemplo, um exercício similar era trabalhado com os alunos de modo que percebessem boas práticas e erros comuns sobre essa competência e, caso necessário, intervenções eram realizadas. Após, os alunos compartilhavam a lição com os demais colegas e discutiam a aplicabilidade para o projeto do jogo.

\section{Apresentação do Software}

O Aventura Matemática remete a ideia de que o jogador irá se aventurar em diferentes cenários virtuais (Bosque, Cidade, Céu, Espaço), como se evoluísse dado a imensidão dos espaços e diante da alusão do crescimento de nível de dificuldade e de conteúdo, em gráficos minimalistas, de modo a tornar lúdico, mas sem desconcentrar os estudos. Em cada cenário, explora-se matérias diferentes, divididas em: (Boque) operações com números inteiros e frações; (Cidade) potenciação, radiciação; (Céu) produtos notáveis; fatoração; (Espaço) expressão algébrica e equações do primeiro e segundo grau.

Os conteúdos são expostos de forma evolutiva, como uma gamificação em fases, de modo que os espaços virtuais são acessíveis somente quando o aluno realiza uma quantidade satisfatória de exercícios da matéria de estudo. Essa funcionalidade remete a solução dada pelos estudantes (Figura 2) e a preferência da orientadora especialista em Matemática quanto às leituras sobre a Aprendizagem Significativa [Ausubel, 1982], principalmente quanto ao entendimento por parte deles que à medida que os educandos compreendem conteúdos mais gerais, podem facilmente compreender os específicos.
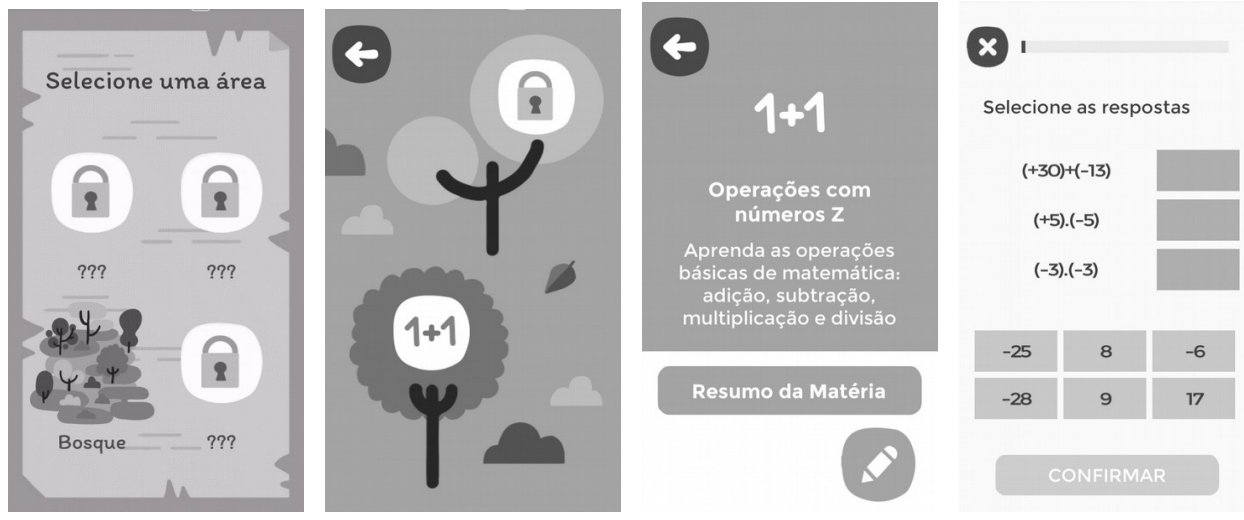

Figura 2. Telas do aplicativo Aventura Matemática [Beltrame et al. 2017]

Dessa forma, para desenvolvimento do jogo foi utilizado mais o conceito de Diferenciação Progressiva da Aprendizagem Significativa, visando a organização, em que o conteúdo de uma determinada disciplina terá maior poder inclusivo. No entanto, algumas práticas sobre Reconciliação Integrativa e Descoberta Autônoma (Figura 3) não fizeram parte da solução, por se preferir que essas ações sejam executadas tendo o jogo como auxiliar nesse processo, ou seja, que os professores e alunos ao utilizarem o objeto de aprendizagem pratiquem dinâmicas complementares não virtuais. 
VII Congresso Brasileiro de Informática na Educação (CBIE 2018)

Anais dos Workshops do VII Congresso Brasileiro de Informática na Educação (WCBIE 2018)

\begin{tabular}{c|ccc}
$\begin{array}{c}\text { Aprendizagem } \\
\text { significativa }\end{array}$ & $\begin{array}{c}\text { Clarificaçãode } \\
\text { relações entre } \\
\text { conceitos }\end{array}$ & $\begin{array}{c}\text { Instrução } \\
\text { audiotutorial } \\
\text { bem planejada }\end{array}$ & $\begin{array}{c}\text { Pesquisa Científica } \\
\text { (nova música ou } \\
\text { arquitetura) }\end{array}$ \\
$\begin{array}{c}\text { Leitura ou a maioria } \\
\text { das apresentações } \\
\text { de livro-texto }\end{array}$ & $\begin{array}{c}\text { Trabalhos escolares } \\
\text { de laboratório }\end{array}$ & $\begin{array}{c}\text { Predomínio da produção } \\
\text { intelectual ou interesse } \\
\text { permanente da pesuisa }\end{array}$ \\
$\begin{array}{c}\text { Tabelas de } \\
\text { multiplicação }\end{array}$ & $\begin{array}{c}\text { Aplicação de fórmulas para } \\
\text { solução de problemas }\end{array}$ & $\begin{array}{c}\text { Soluções "tipo quebra- } \\
\text { cabeça" ensaio e erro }\end{array}$ \\
Aprentica & $\begin{array}{c}\text { Aprendizagem } \\
\text { por recepção }\end{array}$ & $\begin{array}{c}\text { Aprendizagem orientada } \\
\text { para descoberta }\end{array}$ & $\begin{array}{c}\text { Aprendizagem por } \\
\text { descoberta autônoma }\end{array}$ \\
\hline
\end{tabular}

Figura 3. Reconciliação Integrativa e Descoberta Autônoma [Ausubel, 1982]

Em específico, o docente que propor o Aventura Matemática ${ }^{1}$ deve considerar e estimular o fator atitude dos discentes, como um método instrucional que promove independência ao hábito de estudar, compreender o material, e não somente memorizar, fazendo uma conexão lógica com as ideias existentes na estrutura cognitiva do aprendiz. Dessa forma, o jogo propõe um conjunto extenso de exercícios para se resolver a partir da leitura de resumos das matérias, com diferentes opções de visualização das questões. Entretanto, deve o aluno tentar resolver a questão na forma escrita, como se faz em sala de aula ou durante as provas.
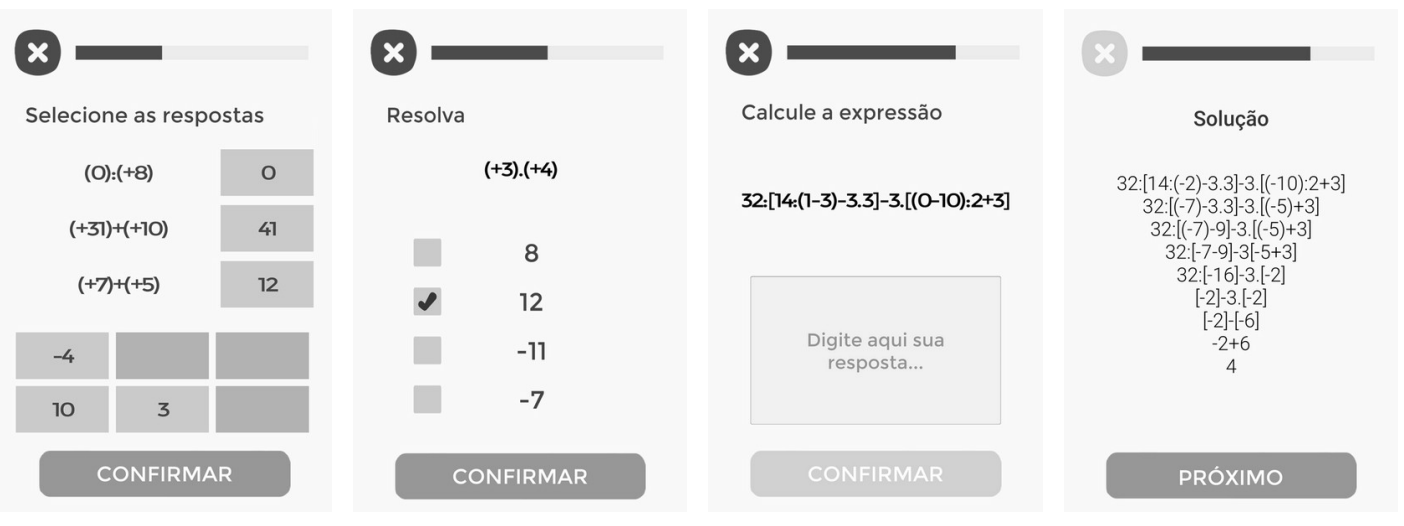

Figura 4. Diferentes tipos de exercícios do Aventura Matemática

Consoante, em Beltrame et al. (2017) foi avaliado que estudantes que utilizaram o jogo segundo essa perspectiva, com leitura dos resumos das matérias e resolução dos exercícios, obteve melhoras na disciplina de Matemática, além de adquirir boas práticas como ler a matéria, realizar anotações e fazer exercícios. Além disso, houve melhora do desempenho em outros currículos, dado que 58,8\% disseram ter utilizado o conteúdo em outras disciplinas, como em Física, e 85,2\% utilizaram em provas de Matemática. No entanto, alguns pontos não foram bem avaliados, como usabilidade, capacidade de manter a atenção do aluno durante um bom período de tempo, capacidade de ser mais prazeroso e a capacidade de interação com outros alunos e professores.

1 https://www.facebook.com/AventuraMatematica 
VII Congresso Brasileiro de Informática na Educação (CBIE 2018)

Anais dos Workshops do VII Congresso Brasileiro de Informática na Educação (WCBIE 2018)

\section{Considerações finais}

Apesar da proposta do jogo ser um facilitador da aprendizagem, algumas decisões de interface não foram trabalhadas satisfatoriamente, de forma que até dificultam alguns meios de visualização e de navegação dos conceitos e práticas. Um dos pontos é que os resumos são apresentados no formato digital PDF (Portable Document Format), que pode ser de difícil leitura em celulares e necessitam de conexão de Internet. Porém, tal opção se deve a essas limitações dos dispositivos móveis e ao esforço necessário para que alunos iniciantes em programação criarem opções avançadas de visualização.

Portanto, outros elementos audiovisuais, como hipertextos, vídeos e formatos interativos, principalmente quanto às funções aritméticas e signos matemáticos, podem proporcionar melhorias em relação a usabilidade e atratividade do jogo. Inserir a opção dos alunos anotarem dúvidas tanto nos conteúdos quanto nos exercícios e soluções é uma alternativa para melhorar a interação com os professores, pela ferramenta ou presencialmente, aumentando as possibilidades de aprendizagem pelo jogo.

Outros pontos quanto a Aprendizagem Significativa estão sendo estudadas para melhoria das funcionalidades do jogo e dizem respeito aos conteúdos e exercícios que poderiam estar relacionados às paisagens do jogo, de modo que sejam motivadoras de questões de investigação e de entendimento das fórmulas com situações-problemas do mundo real (virtualizado nesses cenários), estimulando a capacidade associativa:

1. no Bosque, poderiam ter os cálculos vinculados aos quantitativos das plantas, ou animais, e as figuras geométricas presentes na natureza (um pinheiro tem formato triangular);

2. na Cidade, desafios sobre o trânsito, coleta de lixo, números sobre violências poderiam ser trabalhados e até de forma transdisciplinar, com conceitos de Biologia e Meio Ambiente urbano, Química e poluentes, Sociologia e Geografia;

3. no Céu, poderiam ser trabalhados também questões de Física aplicada a Aeronáutica, Pressão Atmosférica e Camada de Ozônio;

4. Da mesma forma, no Espaço Sideral, questões de Astronomia e até de História, como a corrida espacial durante a Guerra Fria.

Espera-se, com este trabalho, contribuir para o processo de aprendizagem sobre Matemática Básica e sobre como esse processo pode ser apoiado pela Informática na Educação, a partir da utilização de metodologias de aprendizagem por projetos de jogos educacionais, feitos pelos próprios alunos, proporcionando uma revisão de práticas pedagógicas inovadoras e direcionando as perspectivas construtivistas, colaborativas, criativas e ativas na mobilização de jovens para um mundo melhor e solidário.

\section{Referências}

Ausubel, D. P. (1982). A aprendizagem significativa. São Paulo: Moraes.

Beltrame, W.; Baeta, K.D.S.; Souza, M.R.; Piassi, D.F.S.D.; Reboli, G.S.; Sezini, S.L. M.; Favatto, T.S. (2017). Aventura Matemática: Demonstração e Avaliação de um Aplicativo para Aprendizagem de Operações Básicas. In Anais dos WoVygotskyrkshops do Congresso Brasileiro de Informática na Educação (Vol. 6, No. 1, p. 397). 
VII Congresso Brasileiro de Informática na Educação (CBIE 2018)

Anais dos Workshops do VII Congresso Brasileiro de Informática na Educação (WCBIE 2018)

Freire, P. (1998) Pedagogia da Autonomia: saberes necessários à prática educativa. Rio de Janeiro: Paz e Terra.

Medeiros, F.P.A.; Santos Jr, P.S.; Bender, M.; Menegussi, L.; Curcher, M. (2017). A Blended Learning Experience Applying Project-Based Learning in an Interdisciplinary Classroom. In: 10th annual International Conference of Education, Research and Innovation - ICERI.

Nunes, R.R.; Pedrosa, D.; Morgado, L.; Martins, P.; Paredes, H.; Cravino, J.; Barreira, C. (2017). SimProgramming: uma abordagem motivacional para a aprendizagem de alunos intermediários de programação. In Anais dos Workshops do Congresso Brasileiro de Informática na Educação (Vol. 6, No. 1, p. 1099).

Piaget, J. (1929-1979). Conjunto das obras publicadas. Université de Génève. Presses Universitaires de France.

Vygotsky, L.S. (1978). Mind in society: The development of higher psychological processes. Harvard university press. 